\title{
Microenvironment involved in FPR1 expression by human glioblastomas
}

\author{
J. C. Boer ${ }^{1}$ - D. M. S. van Marion ${ }^{1} \cdot$ J. V. Joseph ${ }^{1} \cdot$ N. M. Kliphuis ${ }^{1}$ • \\ H. Timmer-Bosscha ${ }^{1}$ J. A. G. van $\operatorname{Strijp}^{2}$ - E. G. E. de Vries ${ }^{1}$ - W. F. A. den Dunnen ${ }^{3}$. \\ F. A. E. Kruyt ${ }^{1}$ A. M. E. Walenkamp ${ }^{1}$
}

Received: 26 November 2014/ Accepted: 2 April 2015/Published online: 19 April 2015

(C) The Author(s) 2015. This article is published with open access at Springerlink.com

\begin{abstract}
Formyl peptide receptor 1 (FPR1) activity in U87 glioblastoma (GBM) cells contributes to tumor cell motility. The present study aimed to evaluate the FPR1 expression in human GBM, the possibility to elicit agonist induced FPR1 activation of GBM cells and inhibit this activation with chemotaxis inhibitory protein of Staphylococcus aureus (CHIPS). Immunohistochemistry was used to assess FPR1 expression in GBM patient samples, which was present in all 178 samples. Also FPR1 mRNA levels measured with quantitative PCR, could be detected in all 25 GBM patient samples tested. Activation of FPR1 in U87 cells, as measured by human mitochondrial-derived agonists, increased calcium mobilization, AKT and ERK1/2 phosphorylation, and ligand-induced migration. Inhibition of all responses could be achieved with CHIPS. Eight early passage human Groningen Glioma (GG) cell lines, isolated from primary GBM tissue were screened for the presence of FPR1. FPR1 mRNA and protein expression as well as receptor activation could not be detected in any of these early passage GG cell lines. However FPR1 was present in
\end{abstract}

Electronic supplementary material The online version of this article (doi:10.1007/s11060-015-1777-2) contains supplementary material, which is available to authorized users.

A. M. E. Walenkamp

a.walenkamp@umcg.nl

1 Department of Medical Oncology, University Medical Center Groningen, University of Groningen, Hanzeplein 1, P.O. Box 30001, 9700, RB, Groningen, The Netherlands

2 Department of Medical Microbiology, University Medical Center Utrecht, University of Utrecht, Heidelberglaan 100, 3584, CX, Utrecht, The Netherlands

3 Department of Pathology and Medical Biology, University Medical Center Groningen, University of Groningen, Hanzeplein 1, 9700, RB, Groningen, The Netherlands ex vivo tumors formed by the same GG cell lines after being implanted in mouse brains. FPR1 is highly expressed in human GBM specimens, it can be activated by human mitochondrial-derived agonists in U87 and inhibited with CHIPS. FPR 1 cannot be detected in early passage GG cell lines in vitro, however when engrafted in the mouse brain these cells show FPR1 expression. These results suggest a role of the brain microenvironment in FPR 1 expression in GBM.

Keywords FPR1 - GBM $\cdot$ Mitochondrial peptides $\cdot$ GBM cells

\section{Introduction}

Glioblastoma (GBM) accounts for circa $65 \%$ of malignant gliomas $[1,2]$. Treatment options post surgical resection, consist of radiotherapy with concomitant temozolomide resulting in median survival of $12-15$ months $[3,4]$. The highly infiltrative nature of GBM and its seemingly preordained recurrence contribute to the necessity of developing new treatment options. Inhibition of tumor cell migration could be a therapeutic strategy. In this respect the formyl peptide receptor 1 (FPR1) might be of interest. FPR1 is a G-protein coupled receptor (GPCR) originally identified by its capability to mediate phagocytic leukocyte migration. Agonists for FPR1 are formylated peptides such as the bacterial derived fMLF, and mitochondrial derived fMLKLIV and fMMYALF [5]. Additionally supernatant from necrotic tumor cells may activate FPR1 on U87 cells [6]. Formylated peptide induced activation of phagocytic leukocytes can be inhibited by Chemotaxis Inhibitory Protein of Staphylococcus aureus (CHIPS). CHIPS is an immune evasion protein secreted by $S$. aureus [7] and a 
selective inhibitor of FPR1 which potently abrogates the migration of neutrophils and monocytes towards the site of infection [8].

Stimulation of human U87 GBM cells with fMLF elicits the upregulation of hypoxia inducible factor 1-alpha (HIF1 $\alpha)$ [6] and of vascular endothelial growth factor (VEGF) [6, 9]. Moreover FPR1 receptor activation produces downstream protein phosphorylation of ERK1/2 and AKT, which are early signalling events of cell proliferation and migration [10, 11]. In addition these effects can be inhibited by CHIPS [9]. Furthermore, CHIPS treatment showed modest but improved survival of mice with subcutaneously implanted U87 xenografts [9].

In this study we investigated FPR1 expression in human GBM. We analyzed if human mitochondrial peptides could lead to activated FPR1 mediated responses by U87 cells and whether CHIPS could inhibit these responses. In addition early passage Groningen Glioma (GG) cells were screened for functional FPR1 expression and presence of FPR1 mRNA. Finally we compared the presence of FPR1 in human GG cell lines cultured in vitro and implanted in mouse brains.

\section{Materials and methods}

\section{Cells}

The human GBM cell line U87 was purchased from the ATCC (HTB-14) and cultured as previously described [9]. GG lines; GG1, GG6, GG7, GG9, GG12, GG13, GG14 and GG16, isolated from eight primary GBM specimens, were kept at low passage numbers and cultured as previously described [12].

\section{Tissue collection}

A total of $178 \mathrm{GBM}$ patient specimens were collected. Of these, 141 samples were formalin fixed paraffin embedded (FFPE)( 4 cores per tumor) on tissue micro arrays (TMA). In addition 37 frozen specimens with good quality material were used for cryostaining. For 25 specimens sufficient additional tissue was available for quantitative (q)PCR analysis. The paired diagnostic paraffin tumor tissues from which the GG cell lines were isolated was used for comparative staining. Additional control sections of 3 pneumonia and 1 healthy brain tissue were included. All patient samples were retrieved from the tissue bank at the Department of Pathology at the UMCG and collected between 2005-2012 (FFPE samples) and 1998-2007 (cryosections). Tumor tissues were numerically tagged based on a national coding system. According to Dutch law, no further Institutional review and board approval was required.
From NOD scid gamma mice (NOD.Cg-Prkdc ${ }^{\text {scid }}$ $\left.I l 2 \mathrm{rg}^{\mathrm{tm} / \mathrm{Wjl}} / \mathrm{SzJ}\right) / \mathrm{NSG}$ mice), orthotopically implanted with GG12, GG13, GG14 and GG16 FFPE coronal sections were obtained as previously described [12].

\section{$\mathrm{Ca}^{2+}$ mobilization assay}

GPCR activation is measurable by calcium release [13] upon ligand induced receptor activation. Calcium-mobilization by $10^{-6}-10^{-8}$ M fMLKLIV and fMMYALF in U87 cells and $10^{-5} \mathrm{M}$ fMLF in GG cell lines, was performed as previously described [9]. For inhibition experiments, cells pre-incubated with $0.01,0.1,1$ or $10 \mu \mathrm{g} / \mathrm{mL}$ CHIPS for $15 \mathrm{~min}$ at room temperature (RT) were stimulated with $10^{-7} \mathrm{M}$ fMLKLIV and or $10^{-6} \mathrm{M}$ fMMYALF. Stimulation/ inhibition was calculated using the following formula: $\left[\left(\mathrm{MF}_{\text {sample }}-\mathrm{bgF}_{\text {sample }}\right) /\left(\mathrm{MF}_{\max }-\mathrm{bgF}_{\max }\right)\right] \times 100 \%$ in which $\mathrm{MF}_{\text {sample }}=$ mean fluorescence sample, $b g F_{\text {sample }}=$ background fluorescence sample, $\mathrm{MF}=$ mean fluorescence with stimulation and $\mathrm{bgF}=$ background fluorescence without stimulation [14].

\section{Quantitative PCR}

Total RNA extraction was obtained from 25 GBM samples, and GG1, GG6, GG7, GG9, GG12, GG13, GG14, GG16 cell lines. U87 served as a positive control and a no template control (water) served as negative control. RNA was extracted following RNeasy mini kit guidelines (Qiagen, Venlo, The Netherlands) for the GBM samples or with TRIzol ${ }^{\circledR}$-reagent (Ambion Life Technologies, Blijswijk, The Netherlands) by adding $1 \mathrm{~mL}$ of TRIzol ${ }^{\circledR}$ to a $25 \mathrm{~cm}^{2}$ (U87 and GG7) or $75 \mathrm{~cm}^{2}$ culture flask (all other GG cell lines). TRIzol ${ }^{\circledR}$-treated samples were incubated for $10 \mathrm{~min}$, mixed with $200 \mu \mathrm{L}$ chloroform $/ \mathrm{mL}$ TRIzol ${ }^{\circledR}$ and centrifuged each time at $4{ }^{\circ} \mathrm{C}$ and $21,300 \times g$ for $5 \mathrm{~min}$. Samples were incubated with $500 \mu \mathrm{L}$ isopropyl alcohol per $1 \mathrm{~mL} \mathrm{TRIzol}{ }^{\circledR}$ for $10 \mathrm{~min}$ and centrifuged. RNA pellet was washed with $75 \%$ ethanol, centrifuged, air-dried and quantified using a NanoDrop ND-00-spectrophotometer (Thermo Scientific, Breda, The Netherlands). Following Ambion guidelines total RNA was treated with TURBO DNA-free kit; the quality and integrity were detected by ethidium bromide (Invitrogen) staining on $1.2 \%$ agarose gel. Synthesis of cDNA was performed following iSCRIPT guidelines (Bio-Rad Laboratories, Veenendaal, The Netherlands) and quality was checked with a ladder PCR using glyceraldehyde 3-phosphate dehydrogenase (GAPDH) as a loading control. The qPCR was performed using TaqMan Universal Master Mix (Life Technologies) and measured on ABI PRISM 7900HT real-time sequence detection system (Applied Biosystems, Forster City, CA) in a 384-well reaction plate. Primers from Life Technologies 
included FPR1 (HS04235429_S1) and GAPDH (Hs02758991_g1). Raw data was extracted with SDS software 2.3 (Applied Biosystems) and averages of threshold cycles $\left(\mathrm{C}_{\mathrm{T}}\right)$ were used for calculations of relative expression with the $2^{-\Delta \mathrm{ct}}$ method. GAPDH $\mathrm{C}_{\mathrm{T}}$ served as background value with cutoff set at $\mathrm{CT}$ values of 40 cycles.

\section{Immunohistochemistry and staining evaluation}

FFPE $(4 \mu \mathrm{m})$ slides were deparaffinized and rehydrated. Endogenous peroxidase was blocked with $0.33 \% \mathrm{H}_{2} \mathrm{O}_{2}$, antigen retrieval was performed with TrisHCl (pH 9)/microwave. Primary FPR1 antibody (ab\#150533, Abcam, Cambridge, UK) antibody diluted in $1 \%$ bovine serum albumin (BSA)/phosphate buffered saline, $2.7 \mathrm{mM} \mathrm{KCl}$, $1.8 \mathrm{mM} \mathrm{KH} \mathrm{KO}_{4}, 137 \mathrm{mM} \mathrm{NaCl}, 10.1 \mathrm{mM} \mathrm{Na} \mathrm{NPO}_{4}$, $\mathrm{pH}=7.4$ (PBS) was incubated at $4{ }^{\circ} \mathrm{C}$ overnight. Secondary, tertiary antibodies (Table 1) and 3,3-diaminobenzidine (DAB) system were applied and slides were dehydrated and coverslipped.

Snap frozen tissue $(4 \mu \mathrm{m})$ sections were mounted on Starfrost ${ }^{\circledR}$ adhesive slides, dried for 20 min, acetone-fixed for $10 \mathrm{~min}$ and incubated with primary FPR1 antibody (ab\#101659, Abcam) in $1 \%$ BSA/PBS at RT for $1 \mathrm{~h}$. Subsequently, secondary and tertiary antibodies were applied, followed by 3-amino-9-ethylcarbazole (AEC) detection. Slides were mounted with Kaiser's glycerol-gelatin (Millipore Corporation, Amsterdam, the Netherlands). Omission of primary antibody or an appropriate preparation of IgG served as a negative control. Normal brain and pneumonia tissue samples served as controls for antibody specificity. In pneumonia tissue a high FPR1 positivity on infiltrated neutrophils and bronco-alveolar epithelial cell is expected $[15,16]$. In the cerebral cortex a moderate neuron positivity is expected [14].

Immunohistochemical evaluation of TMA was assessed by double blind scoring of slide scans acquired with Aperio ImageScope. Semi-quantitative evaluation was performed by attributing 0 (negative) to 3 (positive) scores. Averages of the 4 cores from both observers representing each patient sample were calculated.

Quantitative evaluation of frozen sections was performed using Olympus WH10-H/22 grid by calculating the percentage of all positive cells counted within the grid in 4 high power fields (400x) randomly selected throughout each tumor slide.

\section{Western blot}

For Western blot analysis U87 cells $\left(1 \times 10^{6}\right)$ were seeded, starved for $24 \mathrm{~h}$ and pre-incubated with culture medium or $10 \mu \mathrm{g} / \mathrm{mL}$ CHIPS for $20 \mathrm{~min}$ at RT. Subsequently, U87 cells were treated for $5,15,30$ min with culture medium only or containing, $10^{-6} \mathrm{M}$ fMMYALF or fMLKLIV. Cells were washed twice with $1.5 \mathrm{~mL}$ ice cold PBS, lysed with $40 \mu \mathrm{L}$ mammalian protein extraction reagent (MPER)(Thermo Scientific) including 1:100 protease (Thermo Scientific), 1:100 phosphatase (Thermo Scientific) inhibitors and incubated for $1 \mathrm{~h}$ on ice. Immunoblotting for phosphorylated Akt(ser473) and ERK1/2 was performed as previously described [9].

\section{Migration}

Eight $\mu \mathrm{m}$ pore-Corning Transwell ${ }^{\circledR}$ polycarbonate membrane cell culture inserts (Sigma-Aldrich, Zwijndrecht, The Netherlands) were coated and blocked as previously described [9]. Lower wells were loaded with $300 \mu \mathrm{L}$ of $10^{-6}$ M fMLF, fMMYALF or fMLKLIV in Dulbecco's modified Eagle's medium high glucose (DMEM-H) $/ 0.5 \%$ BSA. Before treatment U87 cells were serum starved for 2 days and subsequent steps were performed in serum-free DMEM-H medium. Next, $6 \times 10^{5} \mathrm{U} 87$ cells $/ \mathrm{mL}$ were incubated for 15 min with control medium or medium with $10 \mu \mathrm{g} / \mathrm{mL}$ CHIPS. Then, $150 \mu \mathrm{L}$ containing $10^{5} \mathrm{U} 87$ cells were loaded on top of transwell inserts in triplicates. U87 cells migrated towards medium containing $10^{-6} \mathrm{M}$ fMLF, fMMYALF or fMLKLIV for $5 \mathrm{~h}$ at $37{ }^{\circ} \mathrm{C}$ in $5 \% \mathrm{CO}_{2}$ humidified atmosphere. Transwell inserts were cleaned; cells were fixed and counted as previously described [9].

\section{Immunofluorescence}

Paraffin sections of GBM patient specimens $(4 \mu \mathrm{m})$ were deparaffinized, hydrated in demi water, washed with PBS, blocked with PBS/1 \% BSA and stained with anti-FPR1

Table 1 List of antibodies used

\begin{tabular}{lllll}
\hline Antibody & Source & Antigen retrieval & Type & Dilutions and conditions \\
\hline FPR1 & Abcam ab150533 & Tris-HCl, 15 min MW & Rabbit Polyclonal & $1: 250 ; \mathrm{O} / \mathrm{N} \mathrm{4}{ }^{\circ} \mathrm{C}$ \\
& Abcam ab101659 & None & Rabbit Polyclonal & $1: 250 ; 1 \mathrm{~h} \mathrm{RT}$ \\
CD68 & Dako & Tris-HCl, 15 min MW & Mouse Monoclonal & $1: 100 ; \mathrm{O} / \mathrm{N} \mathrm{4}{ }^{\circ} \mathrm{C}$ \\
CD163 & Leica & Tris-HCl, 15 min MW & Mouse Monoclonal & $1: 200 ; \mathrm{O} / \mathrm{N} \mathrm{4}{ }^{\circ} \mathrm{C}$ \\
GFAP & Dako & None & Rabbit Polyclonal & $1: 800 ; \mathrm{O} / \mathrm{N} 4{ }^{\circ} \mathrm{C}$ \\
\hline
\end{tabular}

$M W$ microwave; $\min$ minutes; $\mathrm{O} / \mathrm{N}=$ overnight; $h$ hour; $R T$ room temperature 
antibody (ab\#150533) concomitant either with anti-CD68, anti-CD163 or anti-GFAP (Table 1). Followed by the respective secondary antibodies labeled with either goat antirabbit Alexa 647 (1:400,Invitrogen) or goat anti-mouse Alexa 488 (Invitrogen). Nuclei were counterstained with 4'-6 diamidino-2-phenylindole (DAPI, 1:25000, Sigma) and sections mounted with Vectashield ${ }^{\circledR}$.

\section{Statistical analysis}

Statistical analyses were performed with IBM SPSS statistics version 20. Statistical significance was set at $P<0.05$. A non-parametric Wilcoxon Signed Ranks Test was used to assess differences between ligand induced migration and CHIPS inhibition.

\section{Results}

\section{FPR1 is expressed in all GBM patient samples}

Immunohistochemical analysis of GBM samples (FFPE) showed that FPR1 has a relative diffuse cytoplasmic staining in tumor cells. Blood vessels were negative for FPR1 and served as a negative internal control. All 141 patient samples on TMA showed FPR1 expression. Semiquantitative evaluation of all core biopsies on TMA resulted in an average intensity of 2 (Fig. 1a, b). Six samples displayed 1 negative core and 2 samples contained 2 negative cores. In the remaining specimens all 4 cores stained positive. In 3-control paraffin sections of pneumonia patient samples, FPR1 was highly expressed on both neutrophils and broncho-alveolar epithelial cells as previously described $[15,16]$ (Supplementary Fig. 1a). In healthy brain tissue, neuron cell bodies were slightly FPR1 positive [17] (Supplementary Fig. 1b). Quantitative evaluation of FPR1 in 37 frozen GBM sections resulted in an average amongst all tumors of $33 \pm 14 \%$ of FPR 1 positive cells (Fig. 1c, d). In the frozen sections FPR1 expression was stronger along the cell membranes than in the cytoplasm.

FPR1 mRNA was detected in all 25 GBM patient samples. Values varied from the lowest detectable mRNA levels $\left(2^{-\Delta \mathrm{CT}}=9.34 \times 10^{-4}\right)$ to the highest detectable levels $\left(2^{-\Delta \mathrm{CT}}=1.1 \times 10^{-1}\right)$ (Fig. 1e). These findings indicate that FPR1 is highly expressed in human GBM.

\section{The activation of U87 cells by mitochondrial peptides can be inhibited with CHIPS}

U87 cells stimulated with fMLKLIV and AMMYALF exhibited a dose dependent calcium release up to $37 \pm 15 \%$ (fMLKLIV) and $30 \pm 49 \%$ (fMMYALF) (Fig. 2a, c).
CHIPS treatment completely inhibited calcium release induced by mitochondrial derived fMLKLIV and fMMYALF (Fig. 2b, d; Table 2). These results show that mitochondrial peptides induce calcium mobilization in U87 cells, which can be inhibited with CHIPS.

\section{CHIPS inhibits mitochondrial peptide induced AKT and ERK1/2 phosphorylation in U87}

Stimulation of U87 cells for 5,15 or $30 \mathrm{~min}$ with fMLKLIV or fMMYALF, induced AKT(ser473) phosphorylation (Fig. 2e, f). Densitometric quantification showed that at the same time points, CHIPS pre-treatment inhibited respectively $46 \pm 33,52 \pm 7$ and $67 \pm 12 \%$ of the fMLKLIV-induced phosphorylation (Supplementary Fig. 2a). Similarly in cells stimulated with fMMYALF and pre-treated with CHIPS, respectively $67 \pm 39,78 \pm 29$ and $70 \pm 40 \%$ of fMMYALF-induced AKT phosphorylation was inhibited (Supplementary Fig. 2b). Furthermore fMLKLIV-induced phosporylation of ERK1/2 at 5, 15 and 30 min was completely inhibited with CHIPS (100\%) at all three time points (Fig. 2g) (Supplementary Fig. 2c). Moreover at 5, 15, and $30 \mathrm{~min}$, fMMYALF-induced ERK1/2 phosphorylation could be inhibited up to respectively $94 \pm 16,99 \pm 1$ and $92 \pm 12 \%$ when treated with CHIPS (Fig. 2h)(Supplementary Fig. 2d). This indicates that mitochondrial peptide induced phosphorylation of AKT and ERK1/2 in U87 cells can be potently inhibited with CHIPS.

\section{CHIPS inhibits U87 migration triggered by fMLKLIV, fMMYALF and IMLF}

U87 cells migrated towards the ligands fMLF, fMMYALF and fMLKIV. When preincubating cells with $10 \mu \mathrm{g} / \mathrm{mL}$ CHIPS, cell migration towards fMLF (control), fMMYALF and fMLKLIV was inhibited up to $42 \pm 14 \%$ $(P=0.018), \quad 34 \pm 27 \%(P=0.028)$ and $36 \pm 29 \%$ $(P=0.028)$ respectively (Fig. 2i), indicating that migration of U87 cells towards mitochondrial peptides can be inhibited with CHIPS.

\section{FPR1 activation and mRNA expression could not be detected in GG cell lines}

None of the GG cell lines showed calcium mobilization upon stimulation with fMLF (Supplementary Fig. 3). Additionally FPR1 mRNA could not be detected in any of the 8 GG cell lines while the U87 positive control did exhibit FPR1 mRNA $\left(2^{-\Delta \mathrm{CT}}=2.3 \times 10^{-3}\right)$ (Supplementary Fig. 2e). These results indicate that GG cell lines in vitro retained no functional FPR1 and did not express FPR1 mRNA. 2 
A
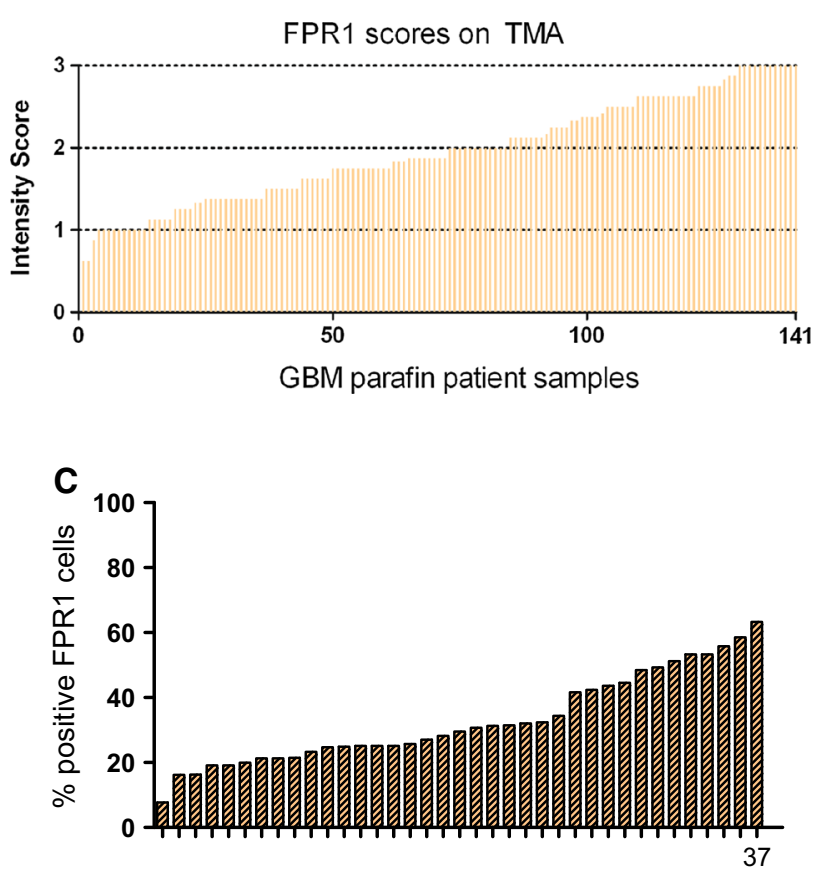

GBM frozen patient samples

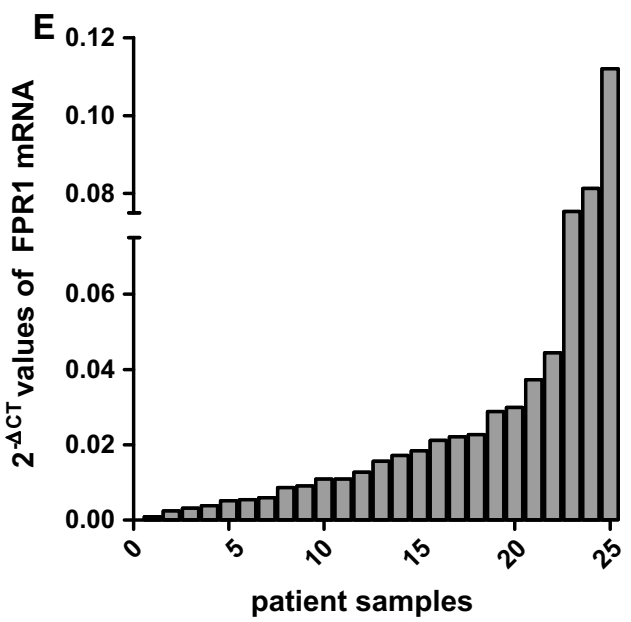

Fig. 1 Detection of FPR1 expression on Tissue Micro Array, frozen sections and qPCR. Bar histogram representing results obtained from a Tissue MicroArray (TMA). Immunohistochemical detection of FPR1 (ab\#150533) expression on formalin fixed-paraffin embedded GBM patient specimens. Semi-quantitative evaluation was performed by averaging the scores of 4 cores derived from each patient specimen and plotted with a corresponding bar. The intensity of FPR 1 expression was scored on a scale from 0 to $3 ; 0$ being negative, 1 positive but with focal and diffuse staining, 2 prevalently focal and more intense staining and 3 exhibiting highly intense focal staining. On average patient

\section{FPR1 is expressed on primary tumor tissue from which GG cell lines were isolated}

The discrepancy between FPR1 expression in GBM patient samples (Fig. 1a-d) and its absence in GG cell lines
B

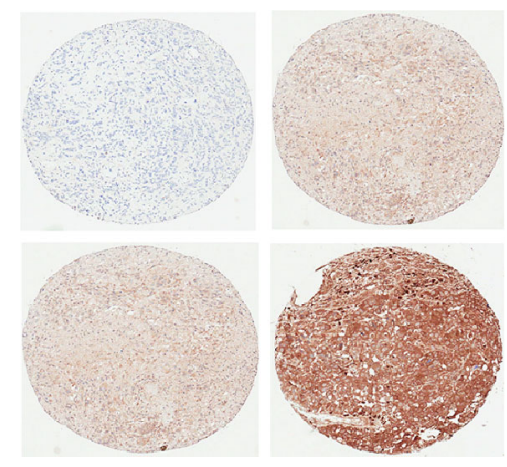

D

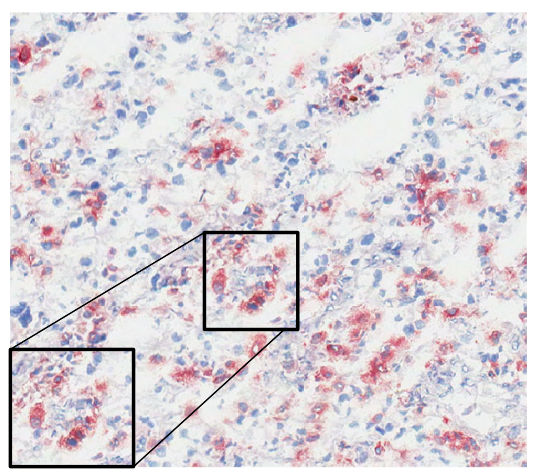

samples exhibited an intensity score of 2 . All samples were positive for FPR1 (a). Representative pictures of 4 different core biopsies containing FPR1 intensities from 0 to 3 (b). Immunohistochemical detection of FPR1 (ab\#101659) expression on 36 frozen GBM patient samples and quantification containing on average $32 \pm 14 \%$ FPR 1 positive cells (c). Representative FPR1 immunohistochemical staining on a frozen GBM section (d). FPR1 mRNA detection on GBM snap frozen tissue samples by qPCR. All samples were loaded in 4 replicates, FPR1 mRNA values varied from minimum $\left(2^{-\Delta \mathrm{CT}}=\right.$ $\left.9.34 \times 10^{-4}\right)$ to maximum $\left(2^{-\Delta \mathrm{CT}}=1.1 \times 10^{-1}\right)(\mathbf{e})$

prompted us to evaluate the primary GBM patient material from which these cells were isolated. Interestingly immunohistochemistry on the paired tumors from which the GG cell lines were originally obtained, all exhibited FPR1 positivity (Fig. 3a-d, Supplementary Fig. 4). 
A

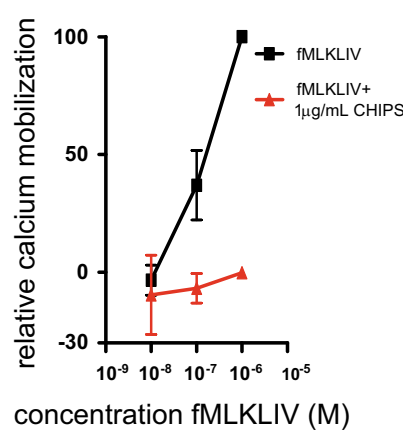

B

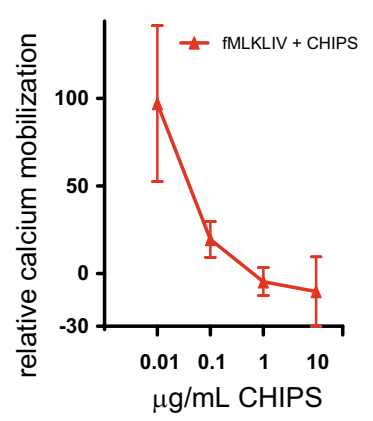

C

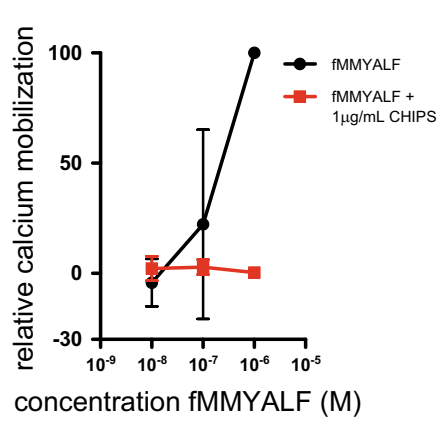

D

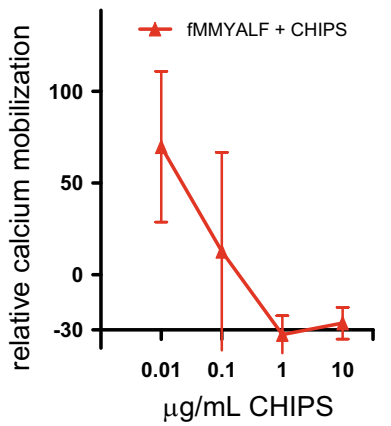

$\mathbf{E}$

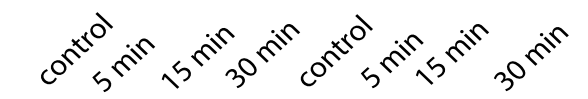

pAKT(ser473)

$\mathbf{F}$

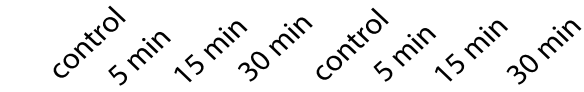

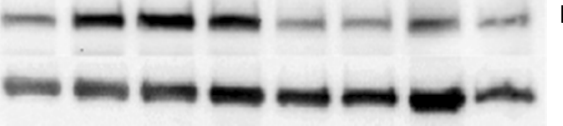

actin

fMLKLIV $10^{-6} \mathrm{M}-\quad+\quad+\quad+\quad+\quad++$

CHIPS

$10 \mu \mathrm{g} / \mathrm{mL}$

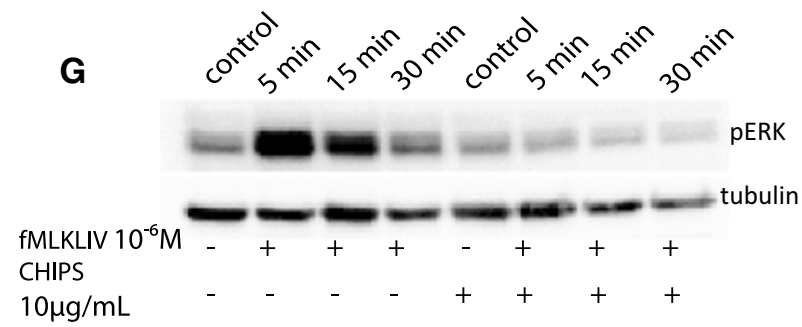

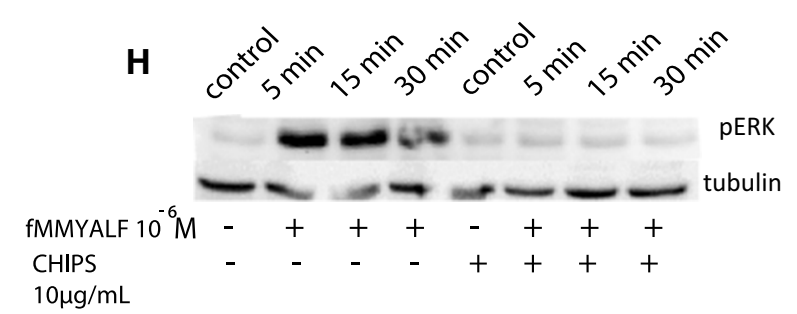

$\begin{array}{lllllllll}\text { fMMYALF } 10 \mathrm{M} & - & + & + & + & - & + & + & + \\ \text { CHIPS } & - & - & - & - & + & + & + & +\end{array}$

$10 \mu \mathrm{g} / \mathrm{mL}$ pAKT(ser 473)

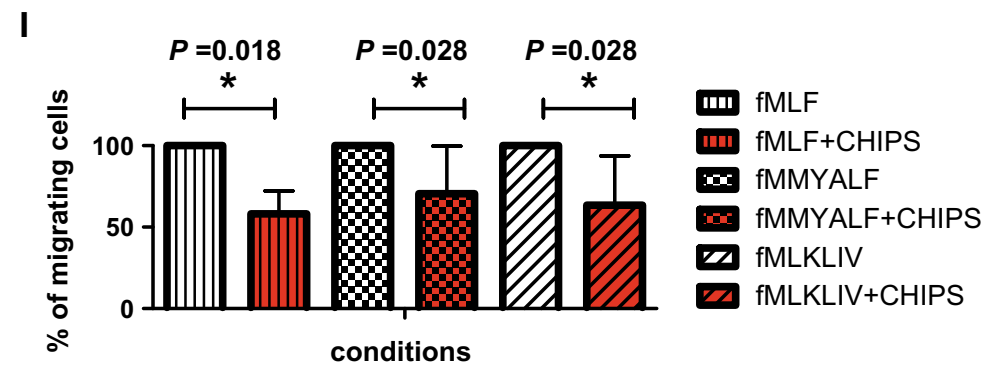

Fig. 2 Inhibition of mitochondrial induced FPR1 activity by CHIPS in U87 cells. Mitochondrial peptides fMLKLIV and fMMYALF induce dose dependent calcium mobilization $\left(10^{-6} \mathrm{M}-10^{-8} \mathrm{M}\right)$ of U87 cells (a, c), which can be dose dependently inhibited with 0.01-10 $\mu \mathrm{g} / \mathrm{mL}$ CHIPS (b, d). In U87 cells $10^{-6} \mathrm{M}$ fMLKLIV or fMMYALF induced AKT phosphorylation on the Ser473 site at 5, 15 and $30 \mathrm{~min}$. At the same time points $10 \mu \mathrm{g} / \mathrm{mL}$ CHIPS showed $46 \pm 33, \quad 52 \pm 7, \quad 67 \pm 12 \%$ inhibition of fMLKLIV induced phosphorylation and respectively $67 \pm 39,78 \pm 29,70 \pm 40 \%$ inhibition of fMMYALF-induced phosporylation $(\mathbf{e}, \mathbf{f})$. A concentration of $10^{-6} \mathrm{M}$ fMLKLIV or fMMYALF induce ERK1/2 phosphorylation in U87 cells at 5, 15 and 30 min. When U87 cells were pre-treated with CHIPS $(10 \mu \mathrm{g} / \mathrm{mL})$, fMLKLIV induced phosphorylation was inhibited up to $100 \%$ and fMMYALF-induced phosphorylation was inhibited $94 \pm 16,99 \pm 1$ and $92 \pm 12 \%$ (respectively at time points 5,15 and $30 \mathrm{~min}$ ) (g and $\mathbf{h}$ ). For migration in transwell assays each time the cell migration towards one of the ligands was set at $100 \%$ and inhibition with CHIPS was plotted against it. Migration towards fMLF, fMMYALF and fMLKLIV of U87 cells was inhibited up to $42 \pm 14 \%(P=0.018), 34 \pm 27 \%$ $(P=0.028)$ and $36 \pm 29 \%(P=0.028)$ when pretreated with $10 \mu \mathrm{g} / \mathrm{mL}$ CHIPS. Values are indicated as mean \pm SD (i) 
Table 2 Ligand induced calcium mobilization with CHIPS inhibition of U87 cells

\begin{tabular}{|c|c|c|c|c|c|}
\hline \multirow[t]{2}{*}{ Concentration } & \multirow[b]{2}{*}{$\begin{array}{l}0 \mu \mathrm{g} / \mathrm{mL} \\
\% \text { stimulation }\end{array}$} & \multirow[b]{2}{*}{$0.01 \mu \mathrm{g} / \mathrm{mL}$} & \multirow[b]{2}{*}{$0.1 \mu \mathrm{g} / \mathrm{mL}$} & \multicolumn{2}{|c|}{ Inhibition with CHIPS (\%) } \\
\hline & & & & $1 \mu \mathrm{g} / \mathrm{mL}$ & $10 \mu \mathrm{g} / \mathrm{mL}$ \\
\hline \multicolumn{6}{|l|}{ fMLKLIV } \\
\hline $10^{-6} \mathrm{M}$ & 100 & - & - & $100 \pm 2$ & - \\
\hline $10^{-7} \mathrm{M}$ & $22 \pm 43$ & $3.0 \pm 34$ & $81 \pm 8$ & $105 \pm 6$ & $110 \pm 15$ \\
\hline $10^{-8} \mathrm{M}$ & $-4.3 \pm 7.3$ & - & - & $100 \pm 2$ & - \\
\hline \multicolumn{6}{|l|}{ fMMYALF } \\
\hline $10^{-6} \mathrm{M}$ & 100 & $30 \pm 31$ & $87 \pm 41$ & $114 \pm 25$ & $126 \pm 6$ \\
\hline $10^{-7} \mathrm{M}$ & $30 \pm 19$ & - & - & $97 \pm 3.8$ & - \\
\hline $10^{-8} \mathrm{M}$ & $-5.0 \pm 6$ & - & - & $98 \pm 5.7$ & - \\
\hline
\end{tabular}

\section{In GBM tissue samples FPR1 is expressed on glial tumor cells and on macrophages}

FPR1 is primarily known for its expression on immune cells [18]. To confirm the presence of FPR1 on tumor cells, double immunofluorescence was performed on GBM patient samples. Results showed FPR1 co-expression with GFAP (Fig. 3e), and also with CD68 and CD163 (Fig. 3f, $\mathrm{g})$. This indicates that FPR1 expression is present on tumor cells as well as on macrophages.

\section{FPR1 expression is present in orthotopic tumors of early passage glioblastoma cells}

The GG cell lines tested were FPR1 negative in vitro, while the paired GBM tissues expressed FPR1 (Fig. 3a-d, Supplementary Fig. 4). Therefore the tumor tissue obtained by orthotopic implantation in the brain of GG cell lines in NOD-SCID IL-2 $\gamma$-knockout mice was evaluated. Tumors were positive with variable intensities (Fig. $4 \mathrm{e}-\mathrm{h}$ ), while all slides from FFPE blocks of cultured GG cell lines were FPR1 negative (Fig. 4a-d). Negative controls are depicted Supplementary Fig. 5. The human nature of the tumors was confirmed with anti-human-nestin staining [12, 19]. These findings suggest that GG cell lines lacking FPR1 in vitro, form tumors with regained receptor expression when intracranially implanted in NOD-SCID IL- $2 \gamma$-knockout mice.

\section{Discussion}

Our findings show that the FPR1 protein is highly expressed in GBM and that its expression is stimulated by the microenvironment. We detected FPR1 expression in a large series of human GBM tumors and showed that the migration of U87 cells is activated by human mitochondrial peptides. Mitochondrial peptide induced activity in U87 cells could be inhibited with CHIPS. FPR1 expression was not detected in 8 early passage cell lines isolated from primary GBM tissue, while their originating tumors did express FPR1. When these cell lines were intracranially injected in mice, the developed tumors regained FPR1 expression thus suggesting a role for the microenvironment in fostering the expression of FPR1.

This is the first time that immunohistochemical FPR1 expression has been investigated in a large series of human GBM tumors. FPR1 immunohistochemistry showed differences in staining patterns for paraffin and frozen human GBM sections. Specifically paraffin sections exhibited a more diffuse cytoplasmic staining while the frozen sections showed stronger membranous staining. This is likely due to differences between the two antibodies used; one being directed against the second extracellular loop and the other directed against the internal region of FPR1. The only other study investigating FPR1 in six GBM patient specimens reported receptor expression in all GBM specimens as detected by immunohistochemistry [6]. Overall our findings of the universal expression of FPR1 in human GBM tumors, together with previous reports on the contribution of FPR1 to the survival benefit of animals treated with siRNA against FPR1 [9, 20], indicate that this receptor might be a interesting target for novel drug development.

GBMs are typically characterized by extensive areas of necrosis. Previous findings showed that the supernatant of necrotic U87 cells activated FPR1 as proven by calcium mobilization and increased chemotaxis [6]. The effects of the necrotic supernatant on FPR1 were probably, at least in part, caused by the presence of free-floating mitochondrial peptides. Mitochondrial peptide affinity and activity on FPR1 was previously reported in transfected HL-60 cells [21]. Together with bacterial peptide fMLF these are the only source formylated peptides in nature and are characterized by highly conserved patterns. This indicates that the ruptured cells in the necrotic GBM microenvironment may affect the broad number of FPR1 positive cells that are present. 

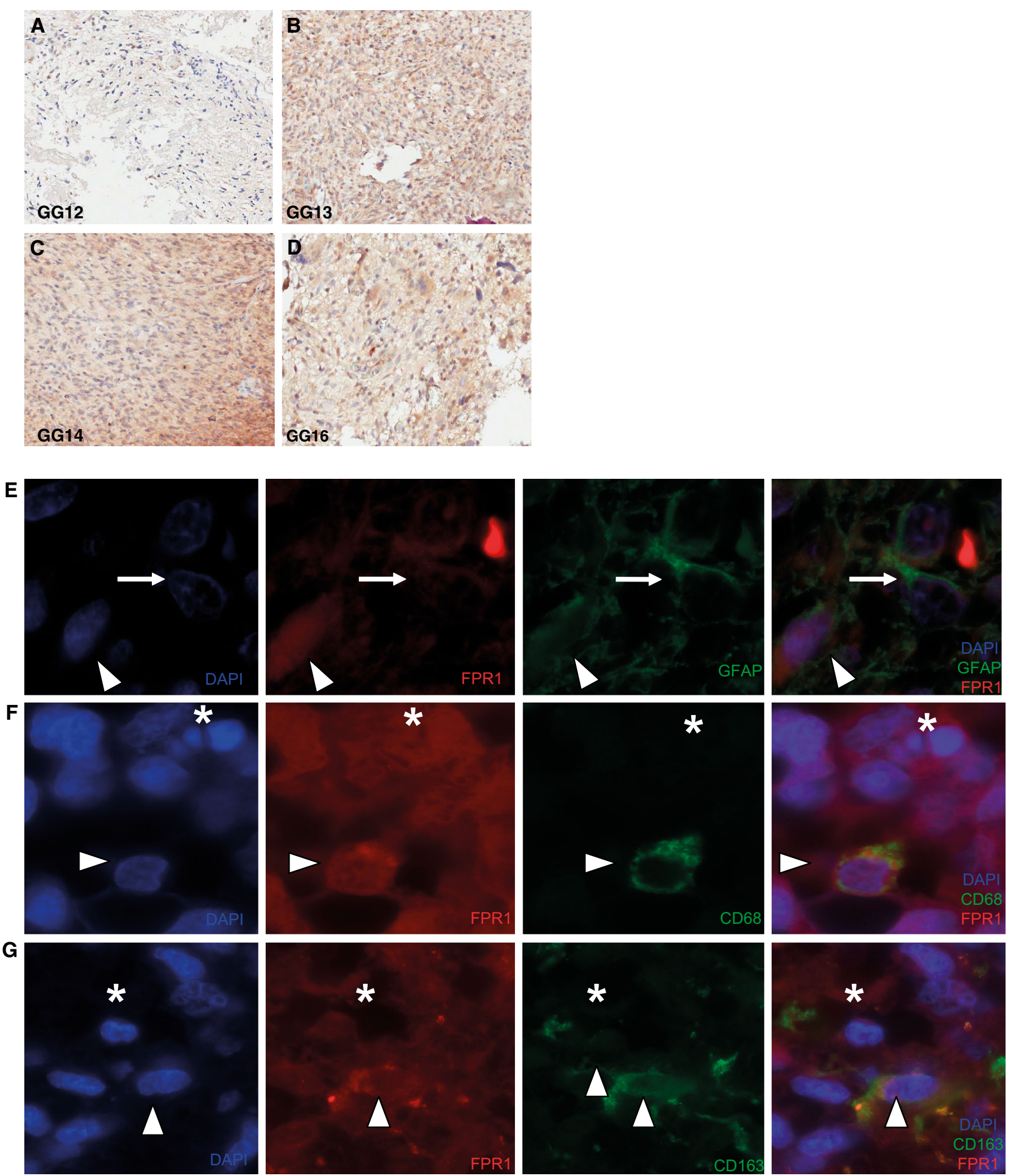

Fig. 3 Immuno -hisotochemical and -fluorescence detection of FPR1 (ab\#150533) alone or coupled with GFAP and CD68/CD163 markers. Representative photomicrographs depicting immunohistochemical expression of FPR1 in the GBM patient specimens and its derived primary GBM cell line. The original patient specimens all displayed FPR1 expression with variable intensities. Images of patient GBM

tissue of which GG cell lines were obtained (a-d). Immunofluorescence image displaying GFAP single expression (arrow) and coexpression with FPR1 (arrow head) (panel e). FPR1 shows single expression (asterisk) and co-expression with CD68 (arrow head) (panel f). Single stained FPR1 cells (asterisk) and co-expression with CD163 (arrow head) (panel g) 

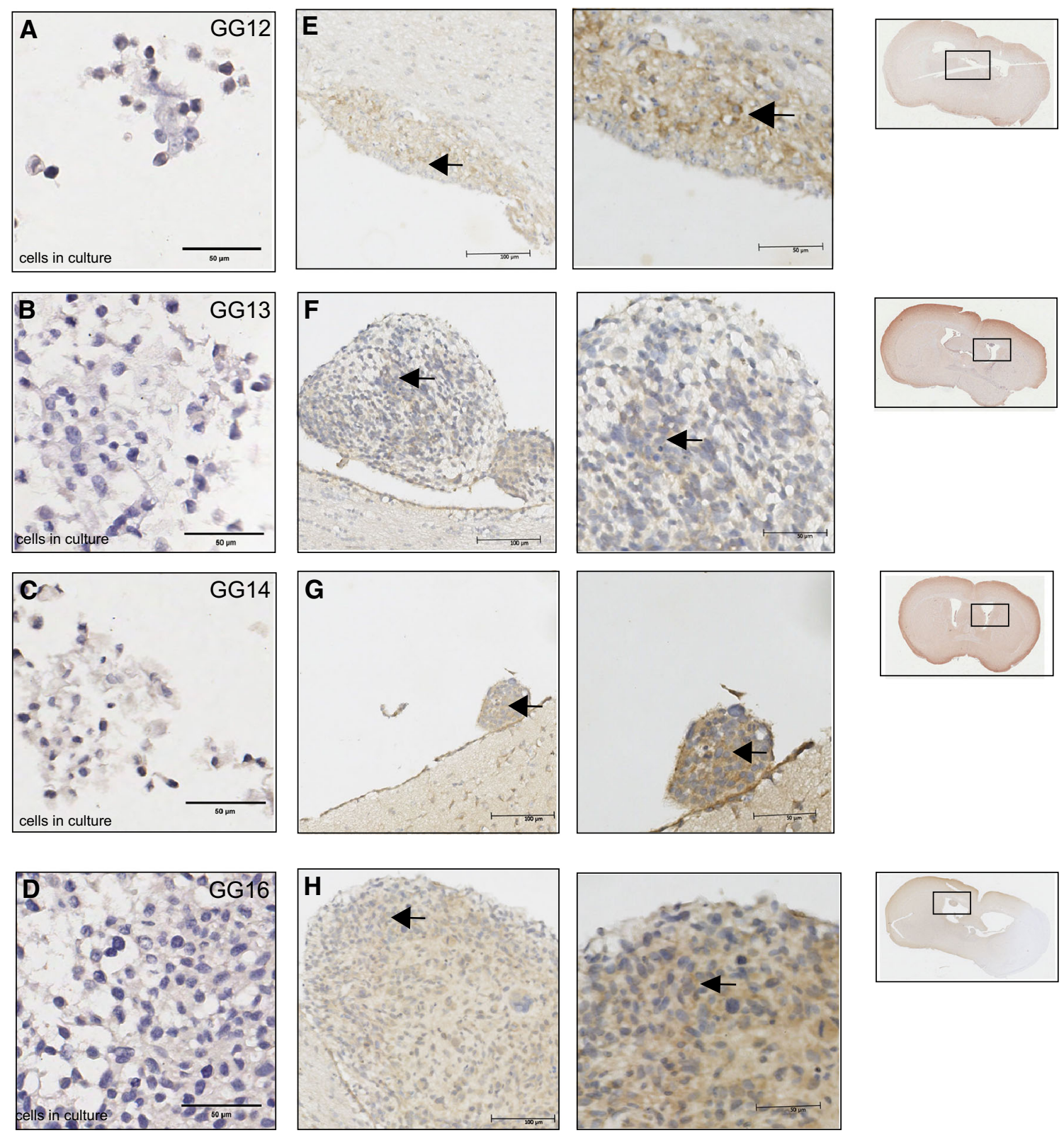

Fig. 4 Immunohistochemical detection of FPR1 (ab\#150533) expression in brain tissue sections of NOD-SCID IL- $2 \gamma$-knockout mice orthotopically injected with GG cell lines. Paraffin embedded samples of the cell lines GG12, GG13, GG14 and GG16 were negative for

We showed for the first time that mitochondrial peptides directly affect the behavior of U87 cells. Activation of the FPR1 expressing U87 GBM cell line by mitochondrial peptides fMLKLIV and fMMYALF elicited calcium mobilization, FPR1 downstream protein phosphorylation and migration. All these responses could be inhibited with CHIPS. Our results are in line with previous findings, which showed a role for FPR1 in malignant tumor cell activity. Namely, incubation of U87 with the bacterial peptide fMLF stimulated cell migration [6], induced the upregulation of HIF-1 $\alpha$ [6] and VEGF [6, 9]. However the
FPR1 (a-d). Mouse brain injected with GG12, GG13, GG14 and GG16 cell lines all showed tumor formation. All tumors expressed FPR1 with variable intensities (panels $\mathbf{e}-\mathbf{h}$ ). Arrow heads indicate the FPR1 positively stained GG cells

use of mitochondrial peptides resembles more closely the conditions of the tumor milieu. Moreover the ability of CHIPS to inhibit all mitochondrial peptide induced responses on U87 cells makes it a potential drug for further investigation.

To further study the effects of the microenvironment on FPR1 we screened a number of early passage GBM cell lines for FPR1 expression. Early passage GBM cell line models are often used to bring new insights into the etiology of GBM [25] and are generally considered to resemble the primary tumor more closely than established 
cell lines [26]. The observation that none of the 8 tested GG cell lines expressed FPR1 was quite unexpected, as all the paired GBM samples did express FPR1. This discrepancy could be the result of heterogeneous FPR1 expression within the tumor or of FPR1 being mostly present on immune cells. In original tumor material, with double immunofluorescence we confirmed that receptor expression occurred in GFAP-positive astrocytic tumor cells as well as on CD68/CD163-positive microglia/macrophages. Huang and colleagues found no co-expression of FPR 1 and GFAP, which led them to conclude that FPR1 is associated with a more undifferentiated cell state [27]. These experiments were performed on U87 cells and thus in an in vitro setting. The GG cell lines were cultured as neurospheres in serum free media supplemented with EGF and FGF, favoring the growth of undifferentiated, cancer stem-like cells [12]. However, we could not detect FPR1 in our early passage GG cell lines. Next we showed that when implanted into mouse brains, the GG cells lacking FPR1 expression in vitro, exhibited the FPR1 membrane expression in vivo. These results show that the GG cell lines still retain the capacity to express FPR1 and suggest that the microenvironment influences the receptor expression of these cells.

Overall, FPR1 is highly expressed in GBMs and the microenvironment plays an important role in modulating FPR1 activation and expression.

Acknowledgments This work was supported by the Dutch Cancer Society (grant number RUG 2010-4622).

Conflict of interest The authors have no financial or personal conflict of interest to declare.

Open Access This article is distributed under the terms of the Creative Commons Attribution 4.0 International License (http://creativecommons.org/licenses/by/4.0/), which permits unrestricted use, distribution, and reproduction in any medium, provided you give appropriate credit to the original author(s) and the source, provide a link to the Creative Commons license, and indicate if changes were made.

\section{References}

1. Louis DN, Ohgaki H, Wiestler OD, Cavenee WK, Burger PC, Jouvet A, Scheithauer BW, Kleihues P (2007) The 2007 WHO classification of tumours of the central nervous system. Acta Neuropathol 114:97-109. doi:10.1007/s00401-007-0243-4

2. Dolecek TA, Propp JM, Stroup NE, Kruchko C (2012) CBTRUS statistical report: primary brain and central nervous system tumors diagnosed in the United States in 2005-2009. Neuro Oncol 14(Suppl 5):v1-v49. doi:10.1093/neuonc/nos218

3. Stupp R, Hegi ME, Mason WP, van den Bent MJ, Taphoorn MJ, Janzer RC, Ludwin SK, Allgeier A, Fisher B, Belanger K, Hau P, Brandes AA, Gijtenbeek J, Marosi C, Vecht CJ, Mokhtari K, Wesseling P, Villa S, Eisenhauer E, Gorlia T, Weller M, Lacombe S, Cairncross JG, Mirimanoff RO, European Organisation for Research and Treatment of Cancer Brain Tumour and Radiation Oncology Groups, National Cancer Institute of Canada
Clinical Trials Group (2009) Effects of radiotherapy with concomitant and adjuvant temozolomide versus radiotherapy alone on survival in glioblastoma in a randomised phase III study: 5-year analysis of the EORTC-NCIC trial. Lancet Oncol 10:459-466. doi:10.1016/S1470-2045(09)70025-7

4. Stupp R, Mason WP, van den Bent MJ, Weller M, Fisher B, Taphoorn MJ, Belanger K, Brandes AA, Marosi C, Bogdahn U, Curschmann J, Janzer RC, Ludwin SK, Gorlia T, Allgeier A, Lacombe D, Cairncross JG, Eisenhauer E, Mirimanoff RO, European Organisation for Research and Treatment of Cancer Brain Tumor and Radiotherapy Groups, National Cancer Institute of Canada Clinical Trials Group (2005) Radiotherapy plus concomitant and adjuvant temozolomide for glioblastoma. N Engl J Med 352:987-996. doi:10.1056/NEJMoa043330

5. Rabiet MJ, Huet E, Boulay F (2005) Human mitochondriaderived $\mathrm{N}$-formylated peptides are novel agonists equally active on FPR and FPRL1, while Listeria monocytogenes-derived peptides preferentially activate FPR. Eur J Immunol 35:2486-2495. doi:10.1002/eji.200526338

6. Zhou Y, Bian X, Le Y, Gong W, Hu J, Zhang X, Wang L, Iribarren P, Salcedo R, Howard OM, Farrar W, Wang JM (2005) Formylpeptide receptor FPR and the rapid growth of malignant human gliomas. J Natl Cancer Inst 97:823-835. doi:10.1093/jnci/dji142

7. de Haas CJ, Veldkamp KE, Peschel A, Weerkamp F, Van Wamel WJ, Heezius EC, Poppelier MJ, Van Kessel KP, van Strijp JA (2004) Chemotaxis inhibitory protein of Staphylococcus aureus, a bacterial antiinflammatory agent. J Exp Med 199:687-695. doi:10.1084/jem.20031636

8. Postma B, Poppelier MJ, van Galen JC, Prossnitz ER, van Strijp JA, de Haas CJ, van Kessel KP (2004) Chemotaxis inhibitory protein of Staphylococcus aureus binds specifically to the C5a and formylated peptide receptor. J Immunol 172:6994-7001

9. Boer JC, Domanska UM, Timmer-Bosscha H, Boer IG, de Haas CJ, Joseph JV, Kruyt FA, de Vries EG, den Dunnen WF, van Strijp JA, Walenkamp AM (2013) Inhibition of formyl peptide receptor in high-grade astrocytoma by CHemotaxis Inhibitory Protein of S. aureus. Br J Cancer 108:587-596. doi:10.1038/bjc. 2012.603

10. Vivanco I, Sawyers CL (2002) The phosphatidylinositol 3-Kinase AKT pathway in human cancer. Nat Rev Cancer 2:489-501. doi: $10.1038 / \mathrm{nrc} 839$

11. Huang C, Jacobson K, Schaller MD (2004) MAP kinases and cell migration. J Cell Sci 117:4619-4628. doi:10.1242/jcs.01481

12. Joseph JV, Conroy S, Tomar T, Eggens-Meijer E, Bhat K, Copray S, Walenkamp AM, Boddeke E, Balasubramanyian V, Wagemakers M, den Dunnen WF, Kruyt FA (2014) TGF-beta is an inducer of ZEB1-dependent mesenchymal transdifferentiation in glioblastoma that is associated with tumor invasion. Cell Death Dis 5:e1443. doi:10.1038/cddis.2014.395

13. Bootman MD, Roderick HL (2011) Using calcium imaging as a readout of GPCR activation. Methods Mol Biol 746:277-296. doi:10.1007/978-1-61779-126-0_15

14. Walenkamp AM, Boer IG, Bestebroer J, Rozeveld D, TimmerBosscha H, Hemrika W, van Strijp JA, de Haas CJ (2009) Staphylococcal superantigen-like 10 inhibits CXCL12-induced human tumor cell migration. Neoplasia 11:333-344

15. Rescher U, Danielczyk A, Markoff A, Gerke V (2002) Functional activation of the formyl peptide receptor by a new endogenous ligand in human lung A549 cells. J Immunol 169:1500-1504

16. Shao G, Julian MW, Bao S, McCullers MK, Lai JP, Knoell DL, Crouser ED (2011) Formyl peptide receptor ligands promote wound closure in lung epithelial cells. Am J Respir Cell Mol Biol 44:264-269. doi:10.1165/rcmb.2010-0246RC

17. Becker EL, Forouhar FA, Grunnet ML, Boulay F, Tardif M, Bormann BJ, Sodja D, Ye RD, Woska JR Jr, Murphy PM (1998) Broad immunocytochemical localization of the formylpeptide 
receptor in human organs, tissues, and cells. Cell Tissue Res 292:129-135

18. Durstin M, Gao JL, Tiffany HL, McDermott D, Murphy PM (1994) Differential expression of members of the N-formylpeptide receptor gene cluster in human phagocytes. Biochem Biophys Res Commun 201:174-179. doi:10.1006/bbrc.1994.1685

19. Joseph JV, Conroy S, Pavlov K, Sontakke P, Tomar T, EggensMeijer E, Balasubramaniyan V, Wagemakers M, den Dunnen WF, Kruyt FA (2015) Hypoxia enhances migration and invasion in glioblastoma by promoting a mesenchymal shift mediated by the HIF1alpha-ZEB1 axis. Cancer Lett. doi:10.1016/j.canlet. 2015.01.010

20. Zhou Y, Bian X, Le Y, Gong W, Hu J, Zhang X, Wang L, Iribarren P, Salcedo R, Howard OM, Farrar W, Wang JM (2005) Formylpeptide receptor FPR and the rapid growth of malignant human gliomas. J Natl Cancer Inst 97:823-835. doi:10.1093/jnci/ dji142

21. Rabiet MJ, Huet E, Boulay F (2005) Human mitochondriaderived $\mathrm{N}$-formylated peptides are novel agonists equally active on FPR and FPRL1, while Listeria monocytogenes-derived peptides preferentially activate FPR. Eur J Immunol 35:2486-2495. doi:10.1002/eji.200526338
22. Bibb MJ, Van Etten RA, Wright CT, Walberg MW, Clayton DA (1981) Sequence and gene organization of mouse mitochondrial DNA. Cell 26:167-180

23. Tapper DP, Clayton DA (1981) Mechanism of replication of human mitochondrial DNA. Localization of the $5^{\prime}$ ends of nascent daughter strands. J Biol Chem 256:5109-5115

24. de Francesco L, Attardi G (1980) Analysis of sequence homology between human and mouse mitochondrial DNA. J Mol Biol 139:85-93

25. Mitra A, Mishra L, Li S (2013) Technologies for deriving primary tumor cells for use in personalized cancer therapy. Trends Biotechnol 31:347-354. doi:10.1016/j.tibtech.2013.03.006

26. Borrell B (2010) How accurate are cancer cell lines? Nature 463:858. doi:10.1038/463858a

27. Huang J, Chen K, Chen J, Gong W, Dunlop NM, Howard OM, Gao Y, Bian XW, Wang JM (2010) The G-protein-coupled formylpeptide receptor FPR confers a more invasive phenotype on human glioblastoma cells. Br J Cancer 102:1052-1060. doi:10.1038/sj.bjc.6605591 